\title{
Capsaicinoid Inheritance in an Interspecific Hybridization of Capsicum annuum $x$ C. chinense
}

\author{
Yayeh Zewdie ${ }^{1}$ and Paul W. Bosland ${ }^{2}$ \\ Department of Agronomy and Horticulture, New Mexico State University, Las Cruces, NM 88003
}

\begin{abstract}
AdDitional INDEX WORDs. chile, pepper, pungency, generation mean, heritability
Abstract. Pungency, caused by the presence of capsaicinoids, is a major quality-determining factor in chile (Capsicum L. sp.) The inheritance of nordihydrocapsaicin, capsaicin, dihydrocapsaicin, isomer of dihydrocapsaicin, and homodihydrocapsaicin has not yet been determined. Generations mean analysis revealed that additive, dominance, and interaction effects were significant for capsaicin, dihydrocapsaicin, and isomer of dihydrocapsaicin in an interspecific hybridization of $C$. annuum L. $x$ C. chinense Jacq. A simple additive-dominance model was sufficient to explain the genetic variation for nordihydrocapsaicin and homodihydrocapsaicin. Except dihydrocapsaicin and isomer of dihydrocapsaicin in the $\mathrm{BCP}_{1}$ family, the values of backcross families shift toward the recurrent parents. Because of the significant additive gene effect and the tendency of the values of the capsaicinoids at backcross families to shift toward the recurrent parents, repeated backcrossing and selection will increase and decrease (depending on the recurrent parent) the capsaicinoid content. Positive genetic correlations were observed between the capsaicinoids and the values ranged from 0.4 to 0.8 . The estimated number of effective factors were 0.4 for nordihydrocapsaicin, 0.6 for homodihydrocapsaicin, 0.9 for isomer of dihydrocapsaicin, 1.1 for dihydrocapsaicin, 2.8 for total capsaicinoids, and 6.2 for capsaicin. Different gene actions and a different number of effective factors involved in the capsaicinoids inheritance imply that different genes are controlling the synthesis of each capsaicinoid.
\end{abstract}

Pungency is a major quality-determining factor in chile (Capsicum sp.) and is caused by the presence of one or more of the 14 capsaicinoids (Kobata et al., 1998). A chile sample may contain partially or all these capsaicinoids. Krajewska and Powers (1988) reported a linear relationship between pungency and the total amount of capsaicinoids. Therefore, the total pungency value of a given sample is obtained by adding the pungency values of the individual capsaicinoids. Total capsaicinoid content in chile varies from zero to more than 300,000 Scoville Heat Units depending upon genotype (DeWitt and Bosland, 1993).

Krajeska and Powers (1988) reported that humans perceive each capsaicinoid differently, i.e., capsaicin, dihydrocapsaicin, and homodihydrocapsaicin cause a very irritating sensation in contrast to nordihydrocapsaicin which causes the least irritating sensation. Therefore, depending on the proportion of specific capsaicinoid present in the chile sample, the sensation of the product could vary. These marked differences in the perception of the capsaicinoids signify the importance of considering each capsaicinoid separately. The array and relative quantity of individual capsaicinoids in a given chile sample is defined as a capsaicinoid profile.

Capsaicinoids are important in both the pharmaceutical and food industries. Capsaicin is a counter-irritant against pain (Sicuteri et al., 1990) and dihydrocapsaicin protects against increased cholesterol levels in guinea pigs (Negulesco et al., 1989). Specific pungency levels must be maintained for food manufacturers to reliably label food products as mild, medium, and hot. Therefore, cultivars must have a pungency level within a specific range to have commercial value. Moreover, progress in improving or manipulating the pungent property depends on the knowledge of the genetic mechanisms for this trait.

Received for publication 22 Nov. 1999. Accepted for publication 26 Feb. 2000 A contribution of New Mexico State University Agricultural Experiment Station, Las Cruces. The cost of publishing this paper was defrayed in part by the payment of page charges. Under postal regulations, this paper therefore must be hereby marked advertisement solely to indicate this fact.

${ }^{1}$ Graduate research assistant.

${ }^{2}$ Professor.
A genetic mechanism for capsaicinoid content has not yet been determined (Ishikawa et al., 1995). Early study using organoleptic tests suggested that the presence or absence of pungency is controlled by a single dominant gene (Deshpande, 1935). Studies quantifying the amount of pungent compounds (total capsaicinoids) using chromatography revealed that the inheritance of the total capsaicinoid content is under polygenic control with transgressive segregation in the $\mathrm{F}_{2}$ generation (Gill et al., 1973; Ohta, 1962). Ishikawa et al. (1995) reported 10 times greater total capsaicinoid content in $\mathrm{F}_{1}$ plants than the pungent parent. In the $\mathrm{F}_{1}$ generation, high capsaicinoid level was a dominant trait (Ahmed et al., 1982; Ohta, 1962). Using generation mean analysis, Ahmed et al. (1982) reported that the estimate of gene effects for additive, dominance, and dominance $\times$ dominance components were significant for total capsaicinoid content.

Genetic studies for individual capsaicinoids have not been conducted. Understanding the mode of inheritance for individual capsaicinoids will enable breeders to manipulate capsaicinoid profiles more effectively. Knowledge of the inheritance of the trait and factors (genotypic and environmental) influencing its expression is important for successful breeding of chile for capsaicinoid content. Therefore, the objective of this research was to determine the mode of inheritance for nordihydrocapsaicin, capsaicin, dihydrocapsaicin, isomer of dihydrocapsaicin, and homodihydrocapsaicin in a $C$. annиum $\times C$. chinense hybridization.

\section{Materials and Methods}

Plant material. A highly pungent parent (200,000 Scoville Heat Units (SHU)), C. chinense 'Habanero', was hybridized to a very low pungent parent (420 SHU), PI 298646 C. апnиит from Spain. Because the generation mean analysis is used to analyze hybrids between two parents that differ as much as possible for the character under analysis (Cherif and Harrabi, 1990), these two genotypes, that are extremes for high and low capsaicinoid content, were selected for hybridization.

HYBRIDIZATION AND POPULATION DEVELOPMENT. In a climate- 
controlled greenhouse with an average daily maximum temperature of $29^{\circ} \mathrm{C}$ and average daily minimum temperature of $18^{\circ} \mathrm{C}$, plants of PI 298646 and 'Habanero' were grown and evaluated to confirm capsaicinoid levels and to observe the uniformity of each line. A single plant of each selected parent was grown in a 1.25$\mathrm{L}$ white plastic pot and used for hybridization. The growing medium was 1 peat : 1 silica sand : 1 sandy loam soil (by volume). In each pot, $18 \mathrm{~g}$ of a slow-release fertilizer (Osmocote 14N4.2P-11.6K; Scott's-Sierra Horticultural Products, Marysville, Ohio) was topdressed at transplanting and again at flowering. At the white bud stage, flowers were emasculated and hand-pollinated on the same day. The pollinated flowers were labeled with the hybridization date and parent names. The $\mathrm{F}_{1}$ and the parental lines were grown in the greenhouse to produce $\mathrm{F}_{2}, \mathrm{BCP}_{1}\left(\mathrm{~F}_{1} \times\right.$ high parent), and $\mathrm{BCP}_{2}\left(\mathrm{~F}_{1} \times\right.$ low parent $)$ seeds. Because of sterility, poor seed set, and poor seed germination, obtaining large numbers of plants was difficult in this interspecific cross and the experiment was conducted with limited numbers of plants in each family. Although reports (Subramanya, 1983; Tanksley and Iglesias-Olivas, 1984) suggested that the deviation from the normal Mendelian segregation is common in interspecific crosses of Capsicum, Shuh and Fontenot (1990) reported an agreement between the results of interspecific and intraspecific hybridization of Capsicum for inheritance of leaf pubescence. Therefore, it was assumed in this experiment that inheritance of capsaicinoids can be determined by using interspecific hybrids.

Screenhouse EXPeriment. In 1997, $\mathrm{P}_{1}, \mathrm{P}_{2}, \mathrm{~F}_{1}, \mathrm{~F}_{2}, \mathrm{BCP}_{1}$, and $\mathrm{BCP}_{2}$ populations were evaluated in a randomized complete block design under a screen house at the Fabian Garcia Science Center, Las Cruces, New Mexico. The average daily maximum temperature of the screen house during the growth period was 33 ${ }^{\circ} \mathrm{C}$ and average daily minimum temperature was $18^{\circ} \mathrm{C}$. Irradiance in the screen house was $50 \%$ of the open field. Seeds of each family were sown in the greenhouse and seedlings were transplanted to $1.25-\mathrm{L}$ white plastic pots in the screen house 4 weeks after sowing. Each treatment was planted in two blocks and the number of plants per treatment and block were variable. The total number of plants evaluated in each family were 15, 14, 10, 9, 7, and 6 for $\mathrm{F}_{2}, \mathrm{BCP}_{2}, \mathrm{~F}_{1}, \mathrm{BCP}_{1}, \mathrm{P}_{2}$, and $\mathrm{P}_{1}$, respectively. The growing medium was 1 peat: 1 silica sand : 1 sandy loam soil (by volume). In each pot, $18 \mathrm{~g}$ of a slow-release fertilizer (Osmocote 14N4.2P-11.6K; Scott's-Sierra Horticultural Products) was topdressed at transplanting and again at flowering. Seedlings were watered twice daily to maintain optimum growth. Mature red succulent fruits were harvested from the first four node positions and then bulked per plant for analysis.

Field experiment. In $1998, \mathrm{~F}_{1}, \mathrm{~F}_{2}, \mathrm{BCP}_{1}$, and $\mathrm{BCP}_{2}$ populations were evaluated along with their parents under field conditions at the Leyendecker Plant Science Research Center (LPSRC), $12 \mathrm{~km}$ south of Las Cruces, New Mexico on glendale loam soil
(Bulloch and Neher, 1980). The average daily maximum temperature of the LPSRC during the growth period was $33^{\circ} \mathrm{C}$ and average daily minimum temperature was $14{ }^{\circ} \mathrm{C}$. Seeds of each family were sown in the greenhouse and seedlings were transplanted to the field 7 weeks after sowing. As in the screen house experiment, a randomized complete block design was used and each treatment was planted in two blocks with variable numbers of plants per plot and family. Total number of plants evaluated in each family were, 27, 24, 22, 16, 12, and 6 for $\mathrm{F}_{2}, \mathrm{BCP}_{1}, \mathrm{BCP}_{2}, \mathrm{P}_{2}$, $\mathrm{P}_{1}$, and $\mathrm{F}_{1}$, respectively. Individual plants were spaced $30 \mathrm{~cm}$ within rows and $100 \mathrm{~cm}$ between rows. Standard growing practices for southern New Mexico were used (Bosland, et al., 1994). The field was furrow irrigated as needed, usually at 7- to 10-d intervals. Mature red succulent fruits were harvested from the first four node positions and then bulked per plant for analysis.

LABORATORY ANALYSIS. The method as described by Collins et al. (1995) to extract, separate, and quantify capsaicinoids using high-performance liquid chromatography (HPLC) was followed. The HPLC data were transformed to parts per million (ppm) or $\mathrm{mg} \cdot \mathrm{kg}^{-1}$. Conversion to Scoville Heat Units can be made by multiplying $\mathrm{ppm}$ or $\mathrm{mg} \cdot \mathrm{kg}^{-1}$ by a factor of 15 . The only capsaicinoids detected in the test populations and studied in this investigation were nordihydrocapsaicin, capsaicin, dihydrocapsaicin, isomer of dihydrocapsaicin, and homodihydrocapsaicin. The sum of these capsaicinoids, i.e., total capsaicinoid content, was also evaluated. Because research results (Ahmed et al., 1982; Gill et al., 1973; Ishikawa et al., 1995; Ohta, 1962) have reported only total capsaicinoid content, it was considered also in this analysis for possible comparison.

DAta ANALYSES. Homogeneity of error variance across the two environments, screen house and field, was tested by the F test (Gomez and Gomez, 1983) and none of the error mean squares were significant for any of the capsaicinoids. Combined analyses of variances for families across the two environments were performed to determine family $\times$ environment interaction for each capsaicinoid using the GLM procedure of SAS (SAS Inst., Inc., 1996). Families were considered as fixed effects while environments were random effects. Significant levels were determined as suggested by McIntosh (1983) for combined analysis. Because there was not a significant difference among family $\times$ environment interactions (Table 1), data of the screen house and field experiments were combined for generation mean analysis. The combined number of plants per family were 42, 36, 33, 23, 18 , and 16 for $\mathrm{F}_{2}, \mathrm{BCP}_{2}, \mathrm{BCP}_{1}, \mathrm{P}_{1}, \mathrm{P}_{2}$, and $\mathrm{F}_{1}$, respectively. Mean, variance, and standard error of the $\mathrm{F}_{1}, \mathrm{~F}_{2}, \mathrm{BCP}_{1}, \mathrm{BCP}_{2}$, and the parents were determined using procedure means of the SAS program. Calculated means and variances were used to estimate the midparent (m), additive [d], and dominance [h] gene effects as described by Rowe and Alexander (1980) following the method for three-parameter model of Mather and Jinks (1977).

Table 1. Mean squares for total capsaicinoids (CAPSD), capsaicin (CAP), dihydrocapsaicin (DH), nordihydrocapsaicin (NDH), isomer of dihydrocapsaicin (ISO), and homodihydrocapsaicin (HD) from six chile families tested across two environments.

\begin{tabular}{|c|c|c|c|c|c|c|c|}
\hline $\begin{array}{l}\text { Source of } \\
\text { variation }\end{array}$ & df & CAPSD & CAP & DH & $\mathrm{NDH}$ & ISO & HD \\
\hline$\overline{\text { Environment (E) }}$ & 1 & $4248304^{\mathrm{NS}}$ & $769436^{\mathrm{NS}}$ & $909095^{*}$ & $17268^{\mathrm{NS}}$ & $5650^{\mathrm{NS}}$ & $573^{\mathrm{NS}}$ \\
\hline Block (environment) & 2 & 418050 & 222913 & 21752 & 302 & 457 & 404 \\
\hline Family (F) & 5 & $91695983^{* *}$ & $33500768^{* *}$ & $14127379^{* * *}$ & $93457^{* *}$ & $12243^{* *}$ & $4884^{* *}$ \\
\hline $\mathrm{F} \times \mathrm{E}$ & 5 & $1162096^{\mathrm{NS}}$ & $291081^{\mathrm{NS}}$ & $318149^{\mathrm{NS}}$ & $6771^{\mathrm{NS}}$ & $743^{\mathrm{NS}}$ & $212^{\mathrm{NS}}$ \\
\hline Error & 10 & 1457126 & 537682 & 255740 & 2263 & 730 & 114 \\
\hline
\end{tabular}

$\widehat{\mathrm{Ns},{ }^{*}, * *}$ Nonsignificant or significant at $P<0.05$ or 0.01 , respectively. 
Table 2. Estimated variance components for total capsaicinoids (CAPSD), capsaicin (CAP), dihydrocapsaicin (DH), nordihydrocapsaicin (NDH), isomer of dihydrocapsaicin (ISO), and homodihydrocapsaicin (HD).

\begin{tabular}{|c|c|c|c|c|c|c|}
\hline $\begin{array}{l}\text { Source of } \\
\text { variation }\end{array}$ & CAPSD & CAP & DH & $\mathrm{NDH}$ & ISO & HD \\
\hline Environment (E) & 100919.3 & -48520.0 & 26121.1 & 494.3 & 310.0 & -13.1 \\
\hline Family (F) & 90533886.0 & 33209687.0 & 13809230.0 & 86687.3 & 11499.5 & 4672.1 \\
\hline $\mathrm{F} \times \mathrm{E}$ & -147514.8 & -123300.5 & 31204.6 & 2254.0 & 6.6 & 48.8 \\
\hline
\end{tabular}

Adequacy of the additive-dominance model was determined by $\chi^{2}$ test with three degrees of freedom and was accepted if $P>0.05$ (nonsignificant $\chi^{2}$ value). The deviation from zero was tested using the normal deviate table for each parameter as suggested by Mather and Jinks (1977). When the three-parameter model was inadequate (significant $\chi^{2}$ value), the interaction terms (additive $\times$ additive [i], additive $\times$ dominance [j], and dominance $\times$ dominance [1]) were computed (Mather and Jinks, 1977). The genetic parameters $(\mathrm{m},[\mathrm{d}],[\mathrm{h}],[\mathrm{i}],[\mathrm{j}]$, and [1]) were tested for significance using unpaired $t$ test. Genetic correlation was determined using the following formula (Burton, 1951): genetic correlation = $\left(\mathrm{cvXYF}_{2}-\mathrm{cvXYF}_{1}\right) /\left(\left(\sigma^{2} \mathrm{XF}_{2}-\sigma^{2} \mathrm{XF}_{1}\right)\left(\sigma^{2} \mathrm{YF}_{2}-\sigma^{2} \mathrm{YF}_{1}\right)\right)^{1 / 2}$, where $\mathrm{cvXYF}_{2}=$ covariance of capsaicinoids $\mathrm{X}$ and $\mathrm{Y}$ in $\mathrm{F}_{2}$ generation, $\mathrm{cvXYF}_{1}=$ covariance of capsaicinoids $\mathrm{X}$ and $\mathrm{Y}$ in $\mathrm{F}_{1}$ generation, $\sigma^{2} \mathrm{XF}_{2}=$ variance of capsaicinoid $\mathrm{X}$ in $\mathrm{F}_{2}$ generation, $\sigma^{2} \mathrm{XF}_{1}=$ variance of capsaicinoid $X$ in $F_{1}$ generation, $\sigma^{2} Y_{2}=$ variance of capsaicinoid $\mathrm{Y}$ in $\mathrm{F}_{2}$ generation, and $\sigma^{2} \mathrm{YF}_{1}=$ variance of capsaicinoid $\mathrm{Y}$ in $\mathrm{F}_{1}$ generation.

Environmental variance $\left(\sigma^{2} \mathrm{E}\right)$ and broad sense heritability $\left(\mathrm{H}_{b}{ }^{2}\right)$ were estimated using the following formula (Ito and Brewbaker, 1991): $\mathrm{H}_{\mathrm{b}}{ }^{2}=\left(\sigma^{2} \mathrm{~F}_{2}-\sigma^{2} \mathrm{E}\right) / \sigma^{2} \mathrm{~F}_{2}$, where $\sigma^{2} \mathrm{E}=1 / 4\left(\sigma^{2} \mathrm{P}_{1}\right.$ $\left.+\sigma^{2} P_{2}+2 \sigma^{2} F_{1}\right), \sigma^{2} F_{2}=$ variance of the $F_{2}$ population, $\sigma^{2} P_{1}=$ variance of the high capsaicinoid content parent, $\sigma^{2} \mathrm{P}_{2}=$ variance of the low capsaicinoid content parent, and $\sigma^{2} F_{1}=$ variance of the $\mathrm{F}_{1}$ population.

The number of effective factors (k), defined as the number of gene pairs in which two true breeding lines differ (Mather and Jinks, 1977), involved in capsaicinoid inheritance was estimated by two different methods: $\mathrm{k}=0.25\left(0.75-\mathrm{h}+\mathrm{h}^{2}\right) \mathrm{D}^{2} /\left(\sigma^{2} \mathrm{~F}_{2}-\sigma^{2} \mathrm{~F}_{1}\right)$ (Burton, 1951) and $\mathrm{k}=\mathrm{D}^{2} / 8\left(\sigma^{2} \mathrm{~F}_{2}-\sigma^{2} \mathrm{~F}_{1}\right)($ Castle, 1921), where $\mathrm{h}$ $=\mathrm{F}_{1}-\mathrm{P}_{2} ; \mathrm{D}=\mathrm{P}_{1}-\mathrm{P}_{2} / \mathrm{P}_{1}-\mathrm{P}_{2}, \mathrm{k}=$ minimum number of effective factors, $P_{1}=$ mean of the highest capsaicinoid content parent, $P_{2}$ $=$ mean of the smallest capsaicinoid content parent, $F_{1}=$ mean of the $F_{1}$ population, $F_{2}=$ mean of the $F_{2}$ population, $\sigma^{2} F_{1}=$ variance of the $F_{1}$ population, and $\sigma^{2} F_{2}=$ variance of the $F_{2}$ population.

\section{Results}

Results of combined analyses of variances for families across the two environments indicated that, except for dihydrocaposaicin, there were no significant differences between environments. The family $\times$ environment interactions for each of the capsaicinoids were also nonsignificant (Table 1). When the estimated variance components of family, environment, and family $\times$ environment interactions were examined, the proportion of the variances for the families were $\geq 97 \%$ for each of the capsaicinoids (Table 2). Therefore, the influence of environment and the interactions were considered negligible in this study.

The capsaicinoid content of the parents differed significantly, as was expected, with 'Habanero' having the highest content (Table 3). For the $F_{1}$ progeny, the means of total capsaicinoids, dihydrocapsaicin, nordihydrocapsaicin, and isomer of dihydrocapsaicin were higher than the midparent value, indicating partial dominance toward the highest parent. In contrast, the $F_{1}$ means for capsaicin and homodihydrocapsaicin were less than the midparent indicating partial dominance toward the lowest

Table 3. Capsaicinoid content (mean $\pm \mathrm{SE}$ ) for $\mathrm{P}_{1}$ 'Habanero', $\mathrm{P}_{2}(\mathrm{PI} 298646)$, and their $\mathrm{F}_{1}, \mathrm{~F}_{2}, \mathrm{BCP}_{1}\left(\mathrm{~F}_{1} \times \mathrm{P}_{1}\right)$, and $\mathrm{BCP}_{2}\left(\mathrm{~F}_{1} \times \mathrm{P}_{2}\right)$.

\begin{tabular}{|c|c|c|c|c|c|c|c|}
\hline \multirow[b]{2}{*}{ Family } & \multicolumn{6}{|c|}{ Content $\left(\mathrm{mg} \cdot \mathrm{kg}^{-1}\right)$} & \multirow{2}{*}{$\begin{array}{l}\text { No. of } \\
\text { plants }\end{array}$} \\
\hline & CAPSD $^{z}$ & CAP & DH & NDH & ISO & HD & \\
\hline$\overline{\mathrm{P}_{1}}$ & $13032 \pm 555$ & $7819 \pm 414$ & $4574 \pm 175$ & $377 \pm 30$ & $163 \pm 13$ & $99 \pm 7$ & 18 \\
\hline $\mathrm{BCP}_{1}$ & $9336 \pm 427$ & $4828 \pm 323$ & $3971 \pm 194$ & $384 \pm 42$ & $85 \pm 17$ & $67 \pm 9$ & 33 \\
\hline $\mathrm{F}_{1}$ & $7116 \pm 460$ & $2437 \pm 190$ & $4168 \pm 260$ & $359 \pm 27$ & $114 \pm 7$ & $37 \pm 3$ & 16 \\
\hline $\mathrm{F}_{2}$ & $4554 \pm 511$ & $1528 \pm 210$ & $2606 \pm 304$ & $311 \pm 40$ & $66 \pm 11$ & $44 \pm 7$ & 42 \\
\hline $\mathrm{BCP}_{2}$ & $1490 \pm 333$ & $426 \pm 99$ & $880 \pm 200$ & $138 \pm 32$ & $32 \pm 7$ & $14 \pm 3$ & 36 \\
\hline $\mathrm{P}_{2}$ & $24 \pm 4$ & $6 \pm 2$ & $9 \pm 3$ & $3 \pm 0$ & $3 \pm 0$ & $3 \pm 0$ & 23 \\
\hline Midparent & 6528 & 3913 & 2292 & 190 & 83 & 51 & \\
\hline
\end{tabular}

$\overline{{ }^{\mathrm{z}} \mathrm{CAPSD}}=$ total capsaicinoids, $\mathrm{CAP}=$ capsaicin, $\mathrm{DH}=$ dihydrocapsaicin, $\mathrm{NDH}=$ nordihydrocapsaicin, ISO = isomer of dihydrocapsaicin, and HD $=$ homodihydrocapsaicin.

Table 4. The range of total capsaicinoids (CAPSD), capsaicin (CAP), dihydrocapsaicin (DH), nordihydrocapsaici (NDH), isomer of dihydrocapsaicin (ISO), and homodihydrocapsaicin (HD) in the parents $\left(\mathrm{P}_{1}\right.$ and $\left.\mathrm{P}_{2}\right)$ and segregating families $\left(\mathrm{BCP}_{1}, \mathrm{BCP}_{2}\right.$, and $\left.\mathrm{F}_{2}\right)$.

\begin{tabular}{lccccc}
\hline \hline & \multicolumn{5}{c}{ Content $\left(\mathrm{mg} \cdot \mathrm{kg}^{-1}\right)$} \\
\cline { 2 - 6 } Family & CAPSD & CAP & DH & NDH & ISO \\
\hline $\mathrm{P}_{2}$ & $15-107$ & $3-36$ & $3-62$ & $3-3$ & $3-3$ \\
$\mathrm{BCP}_{2}$ & $15-5878$ & $3-2069$ & $3-3651$ & $3-660$ & $3-163$ \\
$\mathrm{~F}_{2}$ & $15-10091$ & $3-5637$ & $3-6784$ & $3-904$ & $3-291$ \\
$\mathrm{BCP}_{1}$ & $4187-14902$ & $2200-9121$ & $1630-6327$ & $77-925$ & $3-379$ \\
$\mathrm{P}_{1}$ & $9375-17792$ & $5325-10907$ & $3261-6149$ & $240-782$ & $3-208$ \\
\hline
\end{tabular}


Table 5. Joint scaling test and estimates ( \pm SE) with three-parameter model using six families mean for total capsaicinoids (CAPSD), capsaicin (CAP), dihydrocapsaicin (DH), nordihydrocapsaicin (NDH), isomer of dihydrocapsaicin (ISO), and homodihydrocapsaicin (HD) content in PI 298646 x 'Habanero' hybridization.

\begin{tabular}{|c|c|c|c|c|c|c|}
\hline Parameter $^{2}$ & CAPSD & CAP & $\mathrm{DH}$ & $\mathrm{NDH}$ & ISO & HD \\
\hline$\overline{\mathrm{m}}$ & $6410^{* *} \pm 236$ & $3608^{* * *} \pm 165$ & $2282^{* *} \pm 81$ & $194^{* *} \pm 14$ & $75^{* *} \pm 6$ & $51^{* *} \pm 3$ \\
\hline [d] & $6386^{* *} \pm 236$ & $3602^{* *} \pm 165$ & $2272^{* *} \pm 81$ & $191^{* *} \pm 14$ & $72^{* *} \pm 6$ & $48^{* *} \pm 3$ \\
\hline [h] & $-939^{*} \pm 465$ & $-2109^{* *} \pm 232$ & $1111^{* *} \pm 220$ & $161^{* *} \pm 29$ & $23^{* *} \pm 9$ & $-16^{* *} \pm 4$ \\
\hline$\chi^{2}$ & 34.8 & 63.4 & 26.3 & 2.6 & 21.2 & 3.3 \\
\hline$P$ & $<0.005$ & $<0.005$ & $<0.005$ & $0.50-0.25$ & $<0.005$ & $0.50-0.25$ \\
\hline
\end{tabular}

${ }^{\mathrm{z}_{\mathrm{m}}}=$ midparent, $[\mathrm{d}]=$ additive, and $[\mathrm{h}]=$ dominance.

${ }^{* * * *}$ Significant from zero at $P<0.05$ or 0.01 , respectively, based on normal deviates table.

Table 6. Joint scaling test and estimates ( \pm SE) with six-parameter model using six families mean for total capsaicinoids (CAPSD), capsaicin (CAP), dihydrocapsaicin (DH), and isomer of dihydrocapsaicin (ISO) content in PI 298646 x 'Habanero' hybridization.

\begin{tabular}{|c|c|c|c|c|}
\hline Parameter $^{2}$ & CAPSD & CAP & DH & ISO \\
\hline$\overline{\mathrm{m}}$ & $3090 \pm 2330$ & $-486 \pm 1097$ & $3012^{*} \pm 1339$ & $113^{*} \pm 56$ \\
\hline [d] & $6504^{* *} \pm 278$ & $3907^{* *} \pm 207$ & $2282^{* *} \pm 87$ & $80^{* * *} \pm 6$ \\
\hline [h] & $1829 \pm 5308$ & $5130^{*} \pm 2710$ & $-2782 \pm 2972$ & $-188 \pm 141$ \\
\hline [i] & $3438 \pm 2314$ & $4398^{* * *} \pm 1077$ & $-721 \pm 1336$ & $-30 \pm 56$ \\
\hline [j] & $2685^{*} \pm 1217$ & $991 \pm 792$ & $1617^{* *} \pm 584$ & $-52 \pm 39$ \\
\hline [1] & $2197 \pm 3166$ & $-2207 \pm 1686$ & $3938^{* *} \pm 1737$ & $189^{*} \pm 87$ \\
\hline
\end{tabular}

${ }^{\mathrm{z}_{\mathrm{m}}}=$ midparent,$[\mathrm{d}]=$ additive,$[\mathrm{h}]=$ dominance, $[\mathrm{i}]=$ additive $\times$ additive, $[\mathrm{j}]=$ additive $\times$ dominance, and $[1]=$ dominance $\times$ dominance .

${ }^{*}, * *$ Deviation from zero is significant at $P<0.05$ and 0.01 , respectively, according to unpaired $t$ test.

parent (Table 3). The values of both backcross families shifted toward the recurrent parents, except for dihydrocapsaicin and isomer of dihydrocapsaicin in the $\mathrm{BCP}_{1}$ family.

The ranges of the capsaicinoid content for the five families are presented in Table 4. When the capsaicinoid amounts of individual plants were examined in segregating families, they showed a continuous variation. Thus, it was not possible to classify them into distinct classes. Furthermore, the frequency distribution graph of the backcross families was skewed toward the respective recurrent parents (data not presented). Some plants with higher nordihydrocapsaicin, dihydrocapsaicin, isomer of dihydrocapsaicin, and homodihydrocapsaicin content than the high parent were observed in $\mathrm{BCP}_{1}$ and $\mathrm{F}_{2}$ families.

The joint three-parameter scaling test indicated that an additive-dominance model was adequate to explain the variation for only nordihydrocapsaicin and homodihydrocapsaicin, but not adequate for estimating the genetic parameters for total capsaicinoids, capsaicin, dihydrocapsaicin, nor for an isomer of dihydrocapsaicin based on estimates of $\chi^{2}$ (Table 5). The additive and dominance components of the genetic parameter were significantly different from zero. Further analyses using a joint sixparameter model found that most of the genetic parameters for total capsaicinoids, capsaicin, dihydrocapsaicin, and isomer of dihydrocapsaicin deviated from zero (Table 6). The capsaicin content showed significant additive [d], dominance $[\mathrm{h}]$, and additive $\times$ additive [i] effects. Dihydrocapsaicin had significant additive [d], additive $\times$ dominance [j], and dominance $\times$ dominance [1] gene action. For total capsaicinoids, significant additive $[\mathrm{d}]$ and additive $\times$ dominance $[j]$ and for isomer of dihydrocapsaicin significant additive [d], and dominance $\times$ dominance [1] effects were observed (Table 6).

Results of the Burton (1951) and the Castle (1921) methods in estimating the number of effective factors are reasonably close in agreement for each capsaicinoid (Table 7). The number of effective factors controlling the individual capsaicinoids was variable. For example, the two methods estimated consistently that capsaicin had more than six effective factors, while for nordi- hydrocapsaicin the minimum number of effective factor was estimated as 0.4.

The broad sense heritability estimates for the capsaicinoids ranged from $43 \%$ for capsaicin (the lowest) to $85 \%$ for nordihydrocapsaicin and homodihydrocapsaicin (the highest). The heritability estimate was $72 \%$ for total capsaicinoids (Table 7).

Genetic correlation coefficient values for each pair of capsaicinoids are presented in Table 8 . High genetic correlation

Table 7. Estimate of the minimum number of effective factors involved in total capsaicinoids (CAPSD), capsaicin (CAP), dihydrocapsaicin (DH), nordihydrocapsaicin (NDH), isomer of dihydrocapsaicin (ISO), and homodihydrocapsaicin (HD) inheritance and broad-sense heritability in PI 298646 x 'Habanero' hybridization.

\begin{tabular}{|c|c|c|c|c|}
\hline \multirow[b]{2}{*}{ Capsaicinoids } & \multicolumn{3}{|c|}{ Effective factors } & \multirow[b]{2}{*}{$\begin{array}{c}\text { Heritability } \\
(\%)\end{array}$} \\
\hline & $\begin{array}{l}\text { Burton } \\
(1951)\end{array}$ & $\begin{array}{l}\text { Castle } \\
\text { (1921) }\end{array}$ & $\operatorname{Avg}^{z}$ & \\
\hline$\overline{\text { CAPSD }}$ & 2.8 & 2.8 & 2.8 & 72 \\
\hline CAP & 6.5 & 6.0 & 6.3 & 43 \\
\hline DH & 1.3 & 0.9 & 1.1 & 82 \\
\hline $\mathrm{NDH}$ & 0.4 & 0.3 & 0.4 & 85 \\
\hline ISO & 0.9 & 0.8 & 0.9 & 76 \\
\hline HD & 0.6 & 0.6 & 0.6 & 85 \\
\hline
\end{tabular}

${ }^{\bar{z}}$ Mean of the two methods.

Table 8. Genetic correlation coefficients for pairs of capsaicinoids from hybridization of PI 298646 x 'Habanero'.

\begin{tabular}{lccccc}
\hline \hline & NDH & CAP & DH & ISO & HD \\
\hline NDH $^{z}$ & 1 & & & & \\
CAP & 0.4 & 1 & & & \\
DH & 0.8 & 0.6 & 1 & & \\
ISO & 0.5 & 0.4 & 0.6 & 1 & \\
HD & 0.8 & 0.6 & 0.6 & 0.4 & 1
\end{tabular}

${ }^{\mathrm{z}} \mathrm{NDH}=$ nordihydrocapsaicin, $\mathrm{CAP}=$ capsaicin, $\mathrm{DH}=$ dihydrocapsaicin, $\mathrm{ISO}=$ isomer of dihydrocapsaicin, and $\mathrm{HD}=$ homodihydrocapsaicin. 
values (0.8) were observed between nordihydrocapsaicin and dihydrocapsaicin; and between homodihydrocapsaicin and nordihydrocapsaicin. The lowest genetic correlation value, 0.4 , was observed between capsaicin and nordihydrocapsaicin; between isomer of dihydrocapsaicin and capsaicin; and between homodihydrocapsaicin and isomer of dihydrocapsaicin.

\section{Discussion}

All types of digenic epistasis were shown to be important in affecting inheritance of capsaicin, dihydrocapsaicin, and isomer of dihydrocapsaicin. However, a generalization could not be made, because the type of gene action varied among capsaicinoids. The results suggest that the digenic model with no epistasis describes accurately the quantitative inheritance for nordihydrocapsaicin and homodihydrocapsaicin, but the other capsaicinoids require a model with interactions. The positive additive $\times$ additive [i] estimate for capsaicin suggests that gene pairs are in associated forms (Mather and Jinks, 1977), i.e., only 'Habanero' contributes the genes for increasing the capsaicin content.

The transgressive segregates observed for nordihydrocapsaicin, dihydrocapsaicin, isomer of dihydrocapsaicin, and homodihydrocapsaicin contents implied both parents, 'Habanero' and PI 298646, have an allele contributing for increasing these traits. This is also shown by having negative additive $\times$ additive [i] estimates for these capsaicnoids, i.e., the gene pairs are in dispersive form (Mather and Jinks, 1977).

Because of the significant additive gene effect and the tendency of the capsaicinoid values at backcross generations to shift toward the recurrent parents, implied that repeated backcrossing and selection will increase and decrease (depending on the recurrent parent) the capsaicinoid content. Because industrial needs for chile pungency vary, from low or nonpungent paprika for color to very pungent for pharmaceutical purposes, developing high and low pungent chiles is possible either by repeated backcrossing or recurrent selection.

A lack of distinct classes for the capsaicinoids studied in the segregating families implies quantitative inheritance may explain the variation in capsaicinoid content. Therefore, to better understand the quantitative nature of capsaicinoid inheritance, the effective factors (minimum number of genes) were estimated. The effective factor estimates can be used as a guideline in breeding programs (Kondra and Thomas, 1975). If the effect of different genes in the system are not equal, alleles for increasing the trait are not all concentrated in one parent, and the alleles for decreasing the trait are in another parent, the number of effective factors estimated will be low (Mather, 1979). Therefore, the estimates will be unbiased when the following conditions are met: absence of linkage, gene effects for one parent is plus and for the other parent is minus, all genes are equally important, degree of dominance of all plus factors are the same, and an absence of nonallelic interactions (Burton, 1951). Because of the presence of interallelic interactions and dispersive form of the genes for nordihydrocapsaicin, dihydrocapsaicin, isomer of dihydrocapsaicin, and homodihydrocapsaicin in this study, the estimated effective factors were much lower than could be expected. However, the number of effective factors estimated for capsaicin and total capsaicinoids supports the idea that the capsaicinoids are quantitatively inherited traits. The number of effective factors for total capsaicinoids was lower than that for capsaicin. This could be due to different gene effects observed for individual capsaicinoids, i.e., neutralizations of the effective factors.

The broad-sense heritability of $72 \%$ estimated for total capsaicinoids in this study was lower than an earlier report of $98 \%$ (Gill et al., 1973). Heritability estimates could vary depending on the methods used to calculate the estimate, variation in the genetic material tested, and the environment. When individual capsaicinoids were examined, except for capsaicin, the heritability values were high. A high heritability value indicates a high efficiency of selection for improving the trait.

Martinez and Foster (1998) reported that although the small correlation coefficients are statistically significant, the values below 0.4 have little practical significance because only a small portion of the total variation is accounted. Therefore, the genetic correlation values observed between capsaicin and nordihydrocapsaicin; isomer of dihydrocapsaicin and capsaicin; and homodihydrocapsaicin and isomer of dihydrocapsaicin were small and may be negligible. The high genetic correlation values between nordihydrocapsaicin and dihydrocapsaicin; and between homodihydrocapsaicin and nordihydrocapsaicin, indicates a close genetic relationship between these capsaicinoids. These capsaicinoids have similar chemical structure, except for number of carbons in the chain. The association of the traits in the population have significant impact on selection. For example, the positive genetic correlation of nordihydrocapsaicin and dihydrocapsaicin imply that selection for high dihydrocapsaicin content results also in selection for high nordihydrocapsaicin content or vise versa.

In conclusion, differences in gene action and effective factors may imply that synthesis of each of the capsaicinoids is controlled by different genes. Furthermore, a lack of distinct classes in the segregating families indicates quantitative inheritance explain the variation in capsaicinoid content. Because of the significant additive gene effect, improvement through repeated backcrossing and selection of desirable recombinants from segregating populations could be an effective way to increase or decrease the capsaicinoid content in chile.

\section{Literature Cited}

Ahmed, N., J. Singh, and K.L. Bajaj. 1982. Genetics of capsaicin content in chilli pepper. Capsicum and Eggplant Nswl. 1:32.

Bosland, P.W., A.L. Bailey, and D.J. Cotter. 1994. Growing chiles in New Mexico. N.M. State Univ. (Las Cruces) Coop. Ext. Serv. Guide H-230.

Bulloch, H.E. and R.E. Neher. 1980. Soil survey of Doña Ana County, New Mexico. U.S. Govt. Printing Office, Wash., D.C.

Burton, G.W. 1951. Quantitative inheritance in pearl millet (Pennisetum glaucum ). Agron. J. 43:409-417.

Castle, W.E. 1921. An improved method of estimating the number of genetic factors concerned in cases of blending inheritance. Science 54:223.

Cherif, M. and M. Harrabi. 1990. Generation mean analysis of inheritance of resistance to Pyrenophora teres in barley. Plant Breeding 105:69-74.

Collins, M., L.M. Wasmund, and P.W. Bosland. 1995. Improved method for quantifying capsaicinoids in Capsicum using high-performance liquid chromatography. HortScience 30:137-139.

Deshpande, R.B. 1935. Studies in Indian chillies: IV. Inheritance of pungency in Capsicum annuum L. Indian J. Agr. Sci. 5:513-516.

DeWitt, D. and P.W. Bosland. 1993. The pepper garden. Ten Speed Press, Berkeley, Calif.

Gill, K.S., B.S. Ghai, and J.R. Singh. 1973. Inheritance of amount of capsaicin in chili (Capsicum frutescens $\mathrm{L}$. and $C$. annuum $\mathrm{L}$.). Indian J. Agr. Sci. 43:839-841.

Gomez, K.A. and A.A. Gomez. 1983. Statistical procedures for agricul- 
tural research. Wiley, New York.

Ishikawa, I., J. Taller, S. Sakamoto, Y. Goda, and O. Nunomura. 1995. The genetic analysis of capsaicinoids contents in Capsicum annuum L., C. chinense Jacq. and their backcross generation, p. 83-85. In: Proc. IX Eucarpia mtg. on Genet. and Breeding of Capsicum and Eggplant. 2125 Aug., Budapest, Hungary.

Ito, G.M. and J.L. Brewbaker. 1991. Genetic analysis of pericarp thickness in progenies of eight corn hybrids. J. Amer. Soc. Hort. Sci. 116:1072-1077.

Kobata, K., T. Todo, S. Yazawa, K. Iwai, and T. Watanabe. 1998. Novel capsaicinoid-like substances, capsaite and dihydrocapsaite, from the fruits of a nonpungent cultivar, CH-19 sweet, of pepper (Capsicum annuum L.). J. Agr. Food Chem. 46:1695-1697.

Kondra, Z.P. and P.M. Thomas. 1975. Inheritance of oleic, linoleic, and linolenic acids in seed oil of rapeseed Brassica napus. Can. J. Plant Sci. 55:205-210.

Krajewska, A.M. and J.J. Powers. 1988. Sensory properties of naturally occurring capsaicinoids. J. Food Sci. 53:902-905.

Martinez, E.J.H. and A.E. Foster. 1998. Genetic analysis of heading date and other agronomic characters in barley (Hordeum vulgare L.). Euphytica 99:145-153.

Mather, K. 1979. Historical overview: Quantitative variation and polygenic systems, p. 5-34. In: J.N. Thompson, Jr., and J.M. Thody (eds.). Quantitative genetic variation. Academic Press, New York.

Mather, K. and J.L. Jinks. 1977. Introduction to biometrical genetics.
Chapman and Hall, London.

McIntosh, M.S. 1983. Analysis of combined experiments. Agron. J. 75:153-155

Negulesco, J.A., C.L. Lohse, E.E. Hrabovsky, M.T. Boggs, and D.H. Davis. 1989. Dihydrocapsaicin protects against serum hyperlipidemia in guinea pigs fed a cholesterol-enriched diet. Artery 16:174-188.

Ohta, Y. 1962. Physiological and genetical studies on the pungency of Capsicum. V. Inheritance of pungency. Jpn. J. Genet. 37:169-175 (English summary).

Rowe, K.E. and W.L. Alexander. 1980. Computations for estimating the genetic parameters in joint-scaling tests. Crop Sci. 20:109-110.

SAS Inst., Inc. 1996. SAS software release 6.12. SAS Inst., Inc., Cary, N.C.

Sicuteri, F., M. Fanciullacci, M. Nicolodi, P. Geppetti, B.M. Fusco, S. Marabini, M. Alessandri, and V. Campagnolo. 1990. Substance P theory. A unique focus on the painful and painless phenomena of cluster headache. Headache 30:69-79.

Shuh, D.M. and J.F. Fontenot. 1990. Gene transfer of multiple flowers and pubescent leaf from Capsicum chinense into Capsicum annuum backgrounds. J. Amer. Soc. Hort. Sci. 115:499-502.

Subramanya, R. 1983. Transfer of genes for multiple flowers from Capsicum chinense to Capsicum annuum. HortScience 18:747-749.

Tanksley, S.D. and J. Iglesias-Olivas. 1984. Inheritance and transfer of multiple-flower character from Capsicum chinense into Capsicum annuиm. Euphytica 33:769-777. 